\title{
Radiofrequency thermocoagulation for the treatment of trigeminal neuralgia
}

\author{
ZHENGMING WANG ${ }^{1}$, ZHIJIA WANG ${ }^{2}, \mathrm{KAI} \mathrm{LI}^{3}, \mathrm{XU} \mathrm{SU}^{1}, \mathrm{CHAO} \mathrm{DU}^{1}$ and YU TIAN ${ }^{1}$ \\ Departments of ${ }^{1}$ Neurosurgery, ${ }^{2}$ Radiation and ${ }^{3}$ Anesthesia, The Third Hospital of Jilin University and \\ China-Japan Union Hospital, Changchun, Jilin 130033, P.R. China
}

Received September 2, 2020; Accepted December 18, 2020

DOI: 10.3892/etm.2021.10939

\begin{abstract}
Although microvascular decompression (MVD) should be considered as the first-line treatment for classic trigeminal neuralgia (TN) owing to neurovascular compression of the trigeminal nerve, an increasing number of surgeons prefer radiofrequency thermocoagulation (RFT). RFT is a Gasserian ganglion-level ablative intervention that may achieve immediate pain relief for TN. It is used for emergency management when MVD is not suitable for the patient. As the gold surgical standard of classic trigeminal neuralgia, MVD has the advantage of longer efficacy. However, there are currently no high-quality controlled trials to evaluate the efficacy of MVD and RFT. For the present systematic review, the PubMed, Embase and Cochrane databases (all entries up until July 31, 2020) were searched to identify studies related to RFT in order to provide valuable information for clinical decision-making. The efficacy of the RFT method was evaluated in terms of the initial pain relief percentage, recurrence rate and follow-up time. Furthermore, the incidence rate of various postoperative complications was retrieved. RFT was used for a wider range of applications than MVD, including use for primary (owing to neurovascular compression of the trigeminal nerve), idiopathic and secondary (due to primary neurological diseases) $\mathrm{TN}$, and provided a high rate of initial pain relief and long-term pain control. Although this method has several side effects, the incidence of complications could be reduced by precise cannulation. Furthermore, the complications that occurred were not permanent. Thus, RFT is a safe and effective minimally invasive method of pain relief for patients with $\mathrm{TN}$.
\end{abstract}

Correspondence to: Professor Yu Tian or Professor Chao Du, Department of Neurosurgery, The Third Hospital of Jilin University and China-Japan Union Hospital, 126 Xiantai Street, Changchun, Jilin 130033, P.R. China

E-mail: tianyu@jlu.edu.cn

E-mail: duchao0987@yahoo.com

Key words: trigeminal neuralgia, radiofrequency thermocoagulation, Gasserian ganglion, ablative interventions, complications, recurrence rate

\section{Introduction}

Trigeminal neuralgia (TN) is defined as severe, episodic pain distributed along one or more branches of the trigeminal nerve $(1,2)$. Surgical intervention is performed if pharmacotherapy is unsuccessful, either due to intolerable side effects or poor pain control. Although pharmacotherapy is frequently the preferred treatment option, several patients prefer surgery as a first-line treatment due to its long-lasting effect (3).

Radiofrequency thermocoagulation (RFT) was initially developed by Réthi (4) in 1913, although it was not until 1975 that Sweet (5) demonstrated that it is able to provide effective pain relief. MVD is the first choice of surgical treatment in patients with classical trigeminal neuralgia, while RFT (ablation treatment) should be the preferred choice when an MRI does not show any vascular contact. RFT is also used as an alternative option when a patient is thought unable to tolerate MVD (6). In clinical practice, compared with the invasive technique of MVD, RFT is minimally invasive. RFT has advantages and limitations in terms of its efficacy and complications. Although its side effects may not be permanent, they cannot be entirely excluded. Repeated puncture may cause unnecessary damage, although precise cannulation may reduce the incidence of complications. Inaccurate positioning is the major reason for puncture failure and is considered a significant cause of pain recurrence and complications (7-12). Various techniques and applications, such as CT navigation through use of a 3D template or frameless stereotactic navigation, have been proposed for addressing these issues (13).

As the gold surgical standard treatment of classic trigeminal neuralgia, MVD has the advantage of longer efficacy. However, there are currently no high-quality controlled trials to evaluate the efficacy of MVD and RFT. Therefore, this article evaluates the efficacy and complications of RFT to provide a basis for clinicians to make informed choices.

\section{Materials and methods}

Search strategy. Previous publications written in English were searched using the PubMed, Embase and Cochrane databases. The search included studies that were published up to July 31, 2020. Publications were queried using the following key words, including synonyms and all of their possible combinations: 'Trigeminal neuralgia', 'Tic douloureux', 


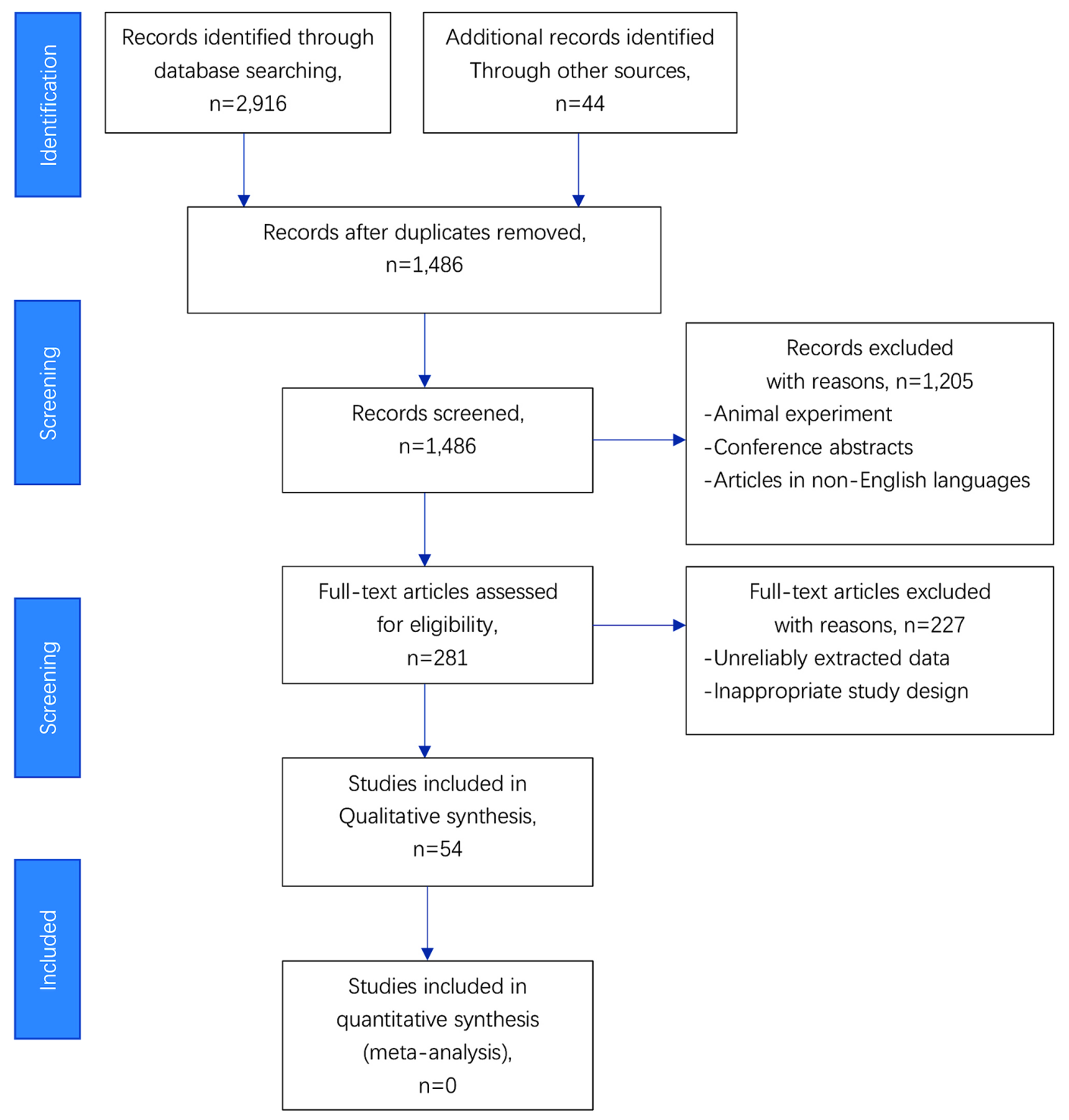

Figure 1. Flow chart depicting the process of study selection.

'trifacial neuralgia', 'radiofrequency thermocoagulation', 'radiofrequency therapy', 'percutaneous radiofrequency ablation', 'radiosurgery', 'radiofrequency ablation', 'radiofrequency thermal coagulation', 'radiofrequency thermal rhizotomy', 'thermocoagulation radiofrequency', 'radiofrequency trigeminal rhizotomy', 'percutaneous infrazygomatic radiofrequency neurolysis' and 'radiofrequency rhizotomy'. The search was limited to research articles involving human subjects. The reference lists of relevant articles were also retrieved and screened during the search. The present review was conducted following the guidelines of the Preferred Reporting Items for Systematic Reviews and Meta-analyses statement and the Cochrane Handbook for Systematic Reviews of Intervention (14), with the exception of protocol registration.

Inclusion and exclusion criteria. All types of studies performed on patients with classical TN undergoing RFT with or without a control group were included. Studies published in a language other than English and conference abstracts were excluded.
Study selection. In total, two authors ( $\mathrm{ZMW}, \mathrm{ZJW}$ ) independently assessed titles and abstracts retrieved via database searches, as well as full texts of potentially relevant studies. Any discrepancies between authors were resolved by involvement of the third author (KL).

Data extraction process. In total, two authors (ZMW, ZJW) independently extracted the following information from each study: Name of the first author, year of publication, study design, comparator, inclusion and exclusion criteria, number of participants, follow-up period, complication rate, initial pain relief rate, recurrence rate and mean time to pain recurrence. Discrepancies were resolved by the third author (SX).

Risk of bias and methodological assessment. In total, two authors with formal training (ZMW, ZJW) performed the assessment of the medical literature according to the principles of evidence-based medicine to determine the risk of bias. The risk of bias of randomized controlled trials (RCTs) was assessed using the Cochrane Risk of Bias Tool (15) and the risk of bias of non-RCTs was performed 


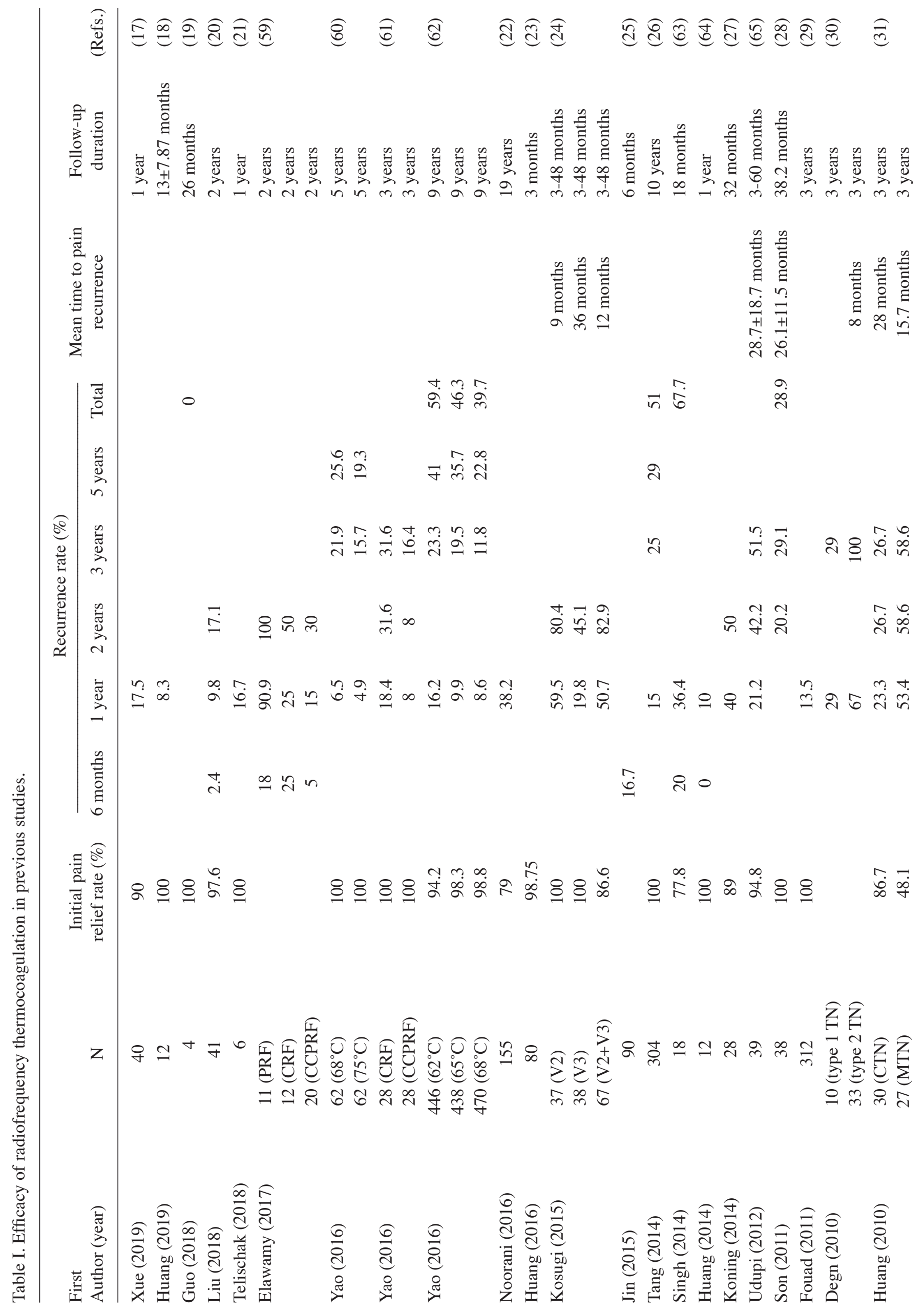


离

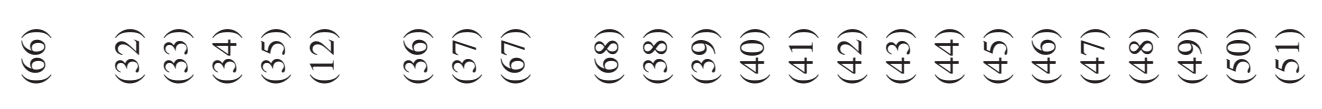

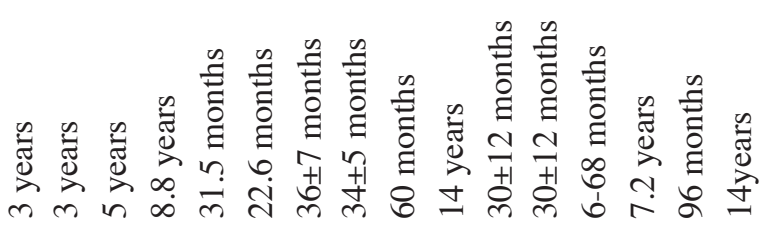

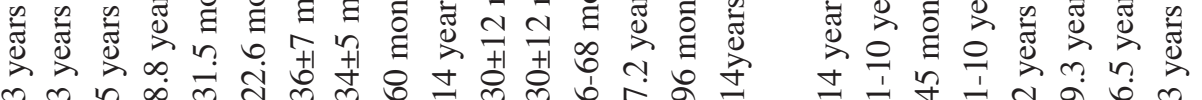

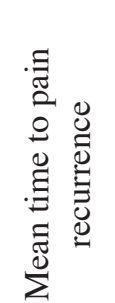
(2)

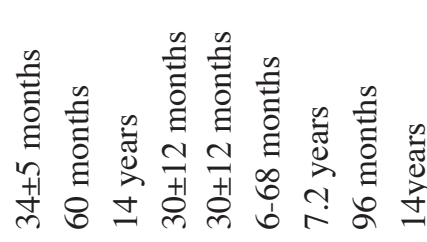

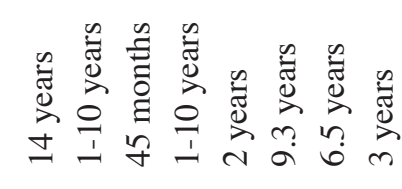

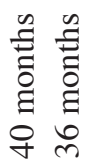

章

$\mid$ 苛

†ำ

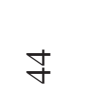

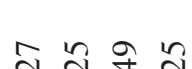

$\stackrel{-}{-} \stackrel{-}{\infty}$

의 훙

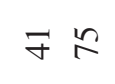

J

ब总

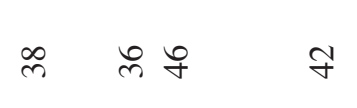

节

$\stackrel{+}{\stackrel{\sim}{*}}$

요유 요

$n$

$\stackrel{+}{\stackrel{4}{4}}$

$\stackrel{\infty}{\mathfrak{I}} \underset{7}{ }$

ב
0
0
0
0

齐

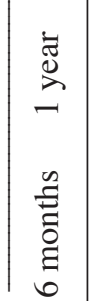

$\underset{\infty}{\infty}$

n

누은

응

고

$\simeq \sqrt{2}$

$\because \quad=$

62

ำ

$\circ \simeq$

灵

产

สุ

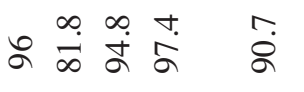

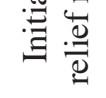

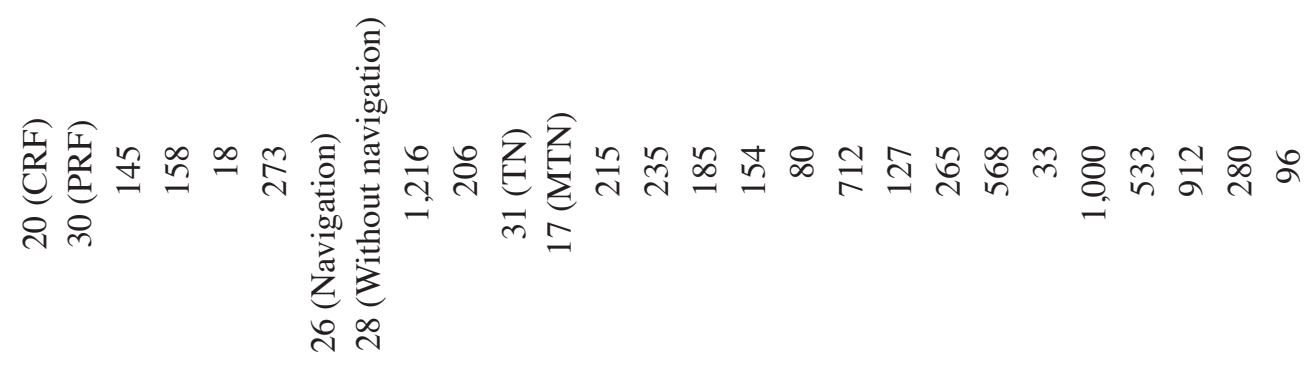

绖

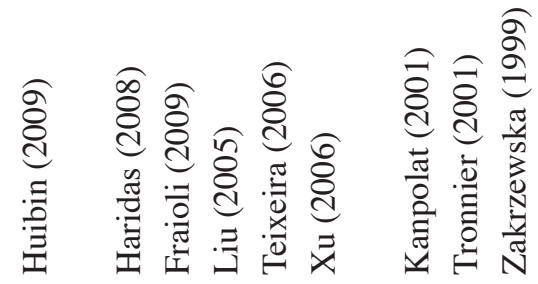

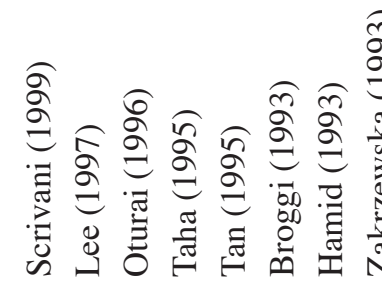

๙ิ

สิ

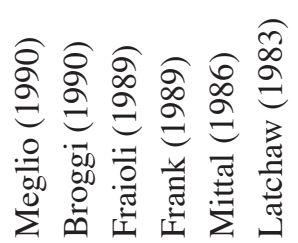




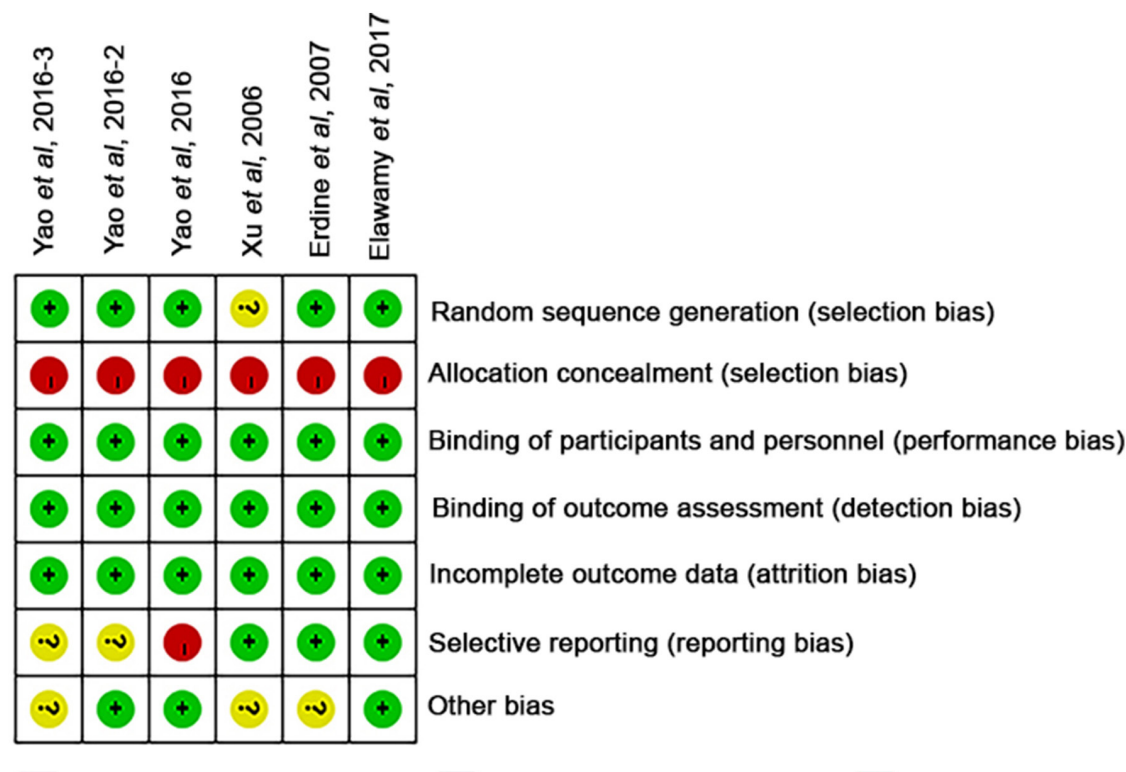

Low risk of bias

Unclear risk of bias

High risk of bias

Figure 2. Overall risk of bias summary of randomized controlled trials.

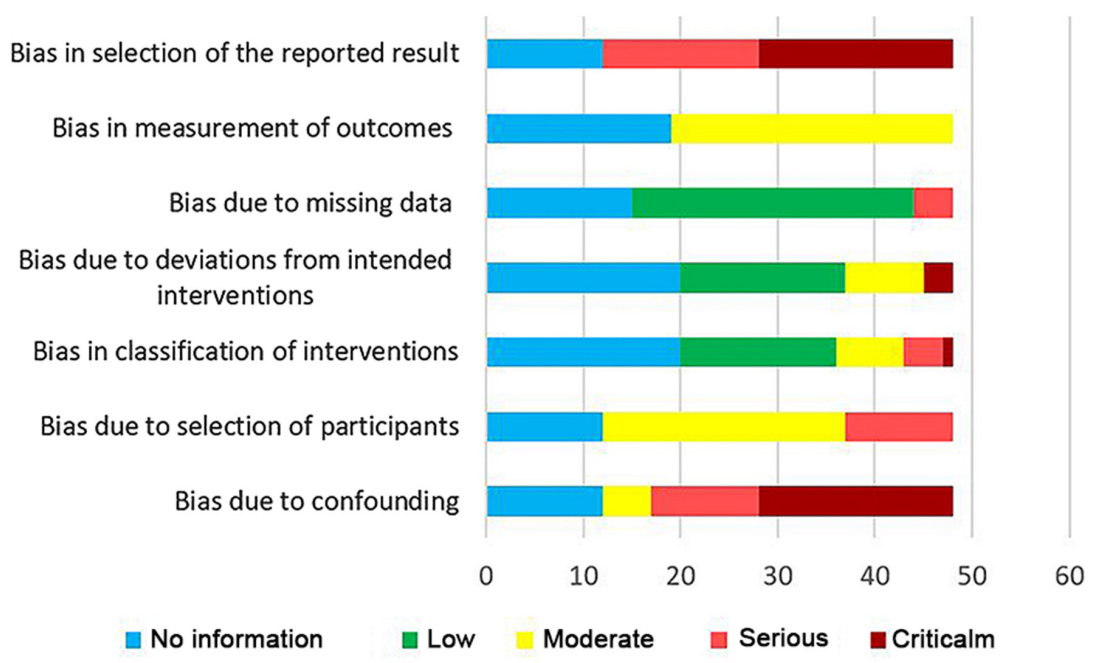

Figure 3. Overall risk of bias summary of non-randomized controlled trials.

using the non-randomized studies of interventions-I tool (16). Discrepancies were resolved by the third author (KL). Due to considerable heterogeneity in the interventions amongst the included studies, along with the difference in the study types, no meta-analysis was performed and the results of the current study are presented in a descriptive fashion.

\section{Results}

Study selection. A flow chart depicting the study retrieval and selection process is presented in Fig. 1. Of the relevant studies identified, 54 studies were included (Tables I and II) in the present review, and 2862 studies were excluded. A total of 13,410 patients were included.

The studies had various designs, including 41 historical cohort studies (17-57) and 13 prospective cohort studies (58-69). Of the 13 prospective cohort studies, six were
RCTs $(59-62,12,69)$ and only one RCT (12) did not describe the method used to generate the allocation sequence in sufficient detail. Despite this, the study was included in the present analysis.

Risk of bias of included studies. The risk of bias summary of the RCTs is presented in Fig. 2 and the risk of bias summary of the non-RCTs is presented in Fig. 3. From all randomized studies, in the first domain, random sequence generation, five studies had a low risk for a particular randomization method. For the allocation concealment domain, all studies had a high risk of bias, because the surgeon knew the personal information of patients. Due to the nature of the intervention, surgical observation studies were difficult to achieve double blinding or triple blinding. Objective evaluation indicators were used so to have minimum effect on the results. Risk of bias for the domain 'blinding of participants and personnel', 'blinding 


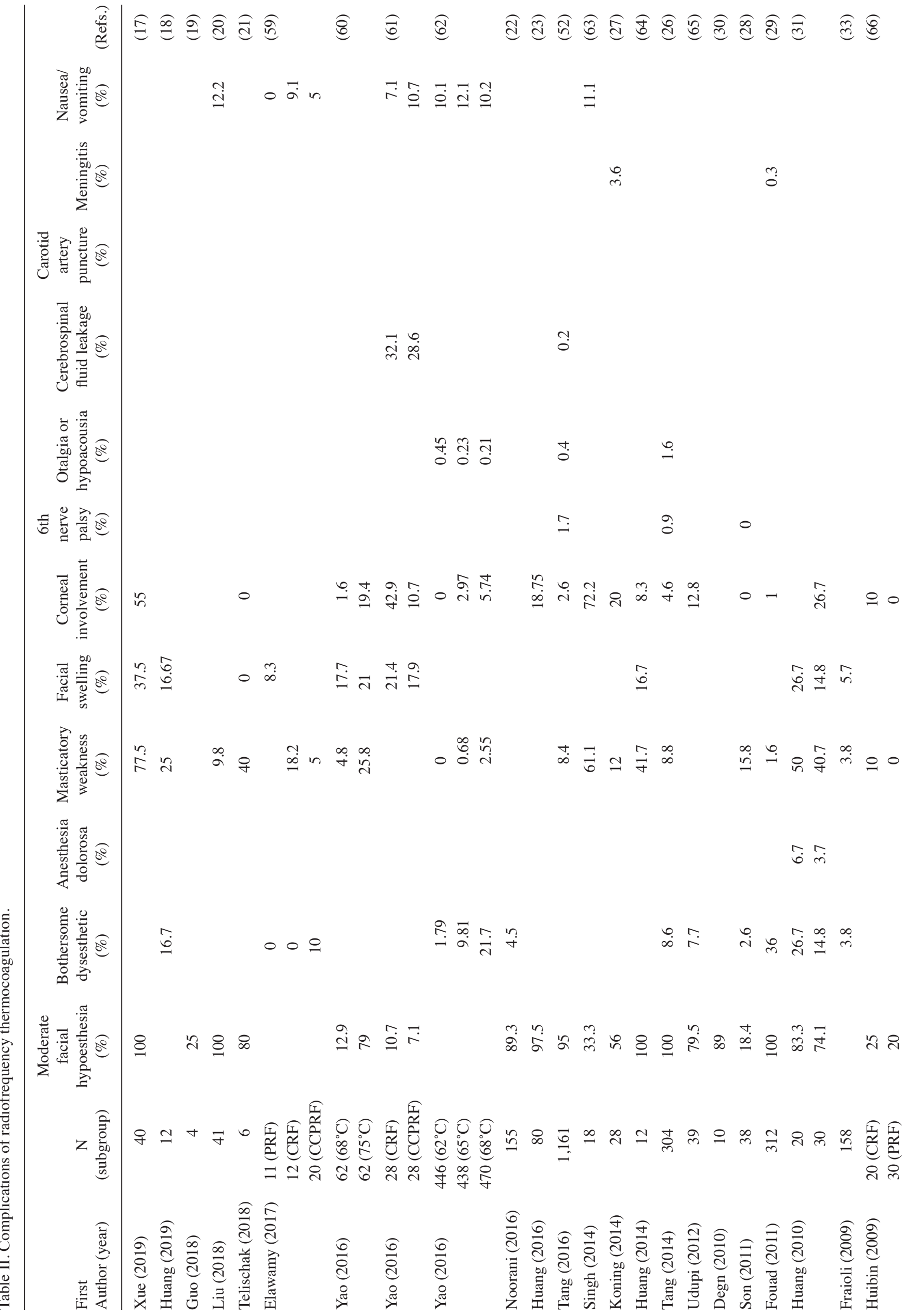




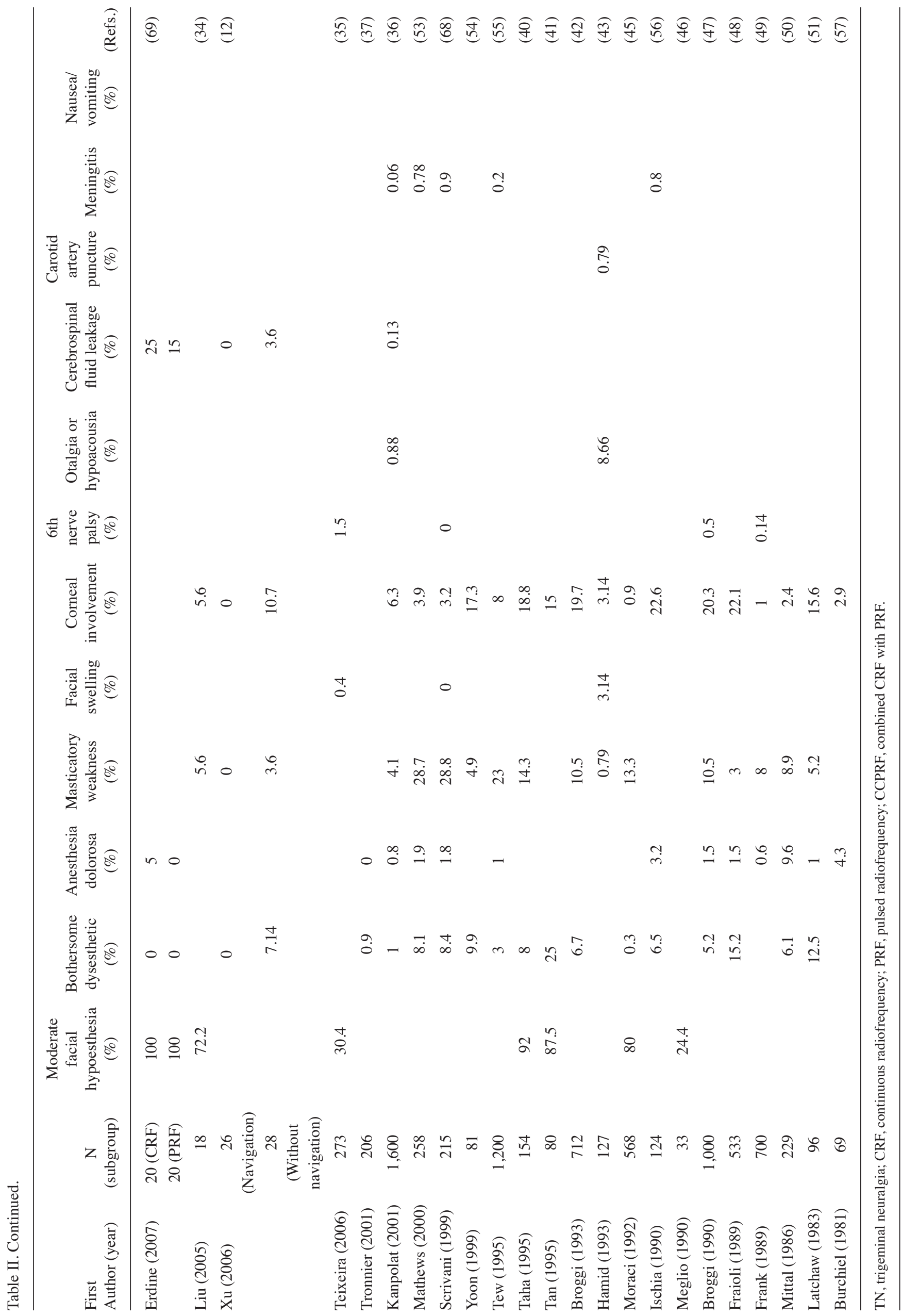


of outcome assessment' and 'In complete outcome data' was defined as low in all studies. In the 'selective reporting' domain, one study was judged to have a high risk of bias and three to have a low risk of bias. In the last domain, other bias, none of the trials was pre-registered, three studies had a low risk of bias due to consistency of methods and results.

Results on efficacy and complications. The percentages of patients experiencing initial pain relief after RFT ranged from 77.8 to $100 \%$ (17-24,26-29,31-35,38,40-43,45-48, $50,58,60-66,68)$, with a mean time to pain recurrence of 8 -40 months $(24,28,30,31,44,65,67)$. The recurrence rate following RFT ranged from 0 to $26 \%(20,25,32,34,39,50$, $51,59,63,64,67)$ at 6 months, from 4.5 to $67 \%(17,18,20-22$, $24-27,29-32,35,36,39,50,51,59-65,12,67)$ at 1 year, from 8 to $82.9 \%(20,24,27,28,31,32,36,37,39,46,51,59-61,65,12,67)$ at 2 years, from 11.8 to $58.6 \%(26,28,30-32,36,39,47,49,51$, $60-62,65,66,67)$ at 3 years and from 15 to $75 \%(26,32,36$, $37,39,40,51,60,62,66,67)$ at 5 years (Table I). All statistical results are continuous radiofrequency (CRF). Pulsed radiofrequency (PRF) and combined CRF with PRF (CCPRF) are not included. There were two studies that $(26,63)$ separately counted the results of mixed TN (MTN). Since other studies did not discuss MTN separately, the results of MTN were not included in the statistics. Only one study (25) discusses type 2 TN (a constant burning, dull background pain), these results were also excluded. The results for MTN and type 2 can be viewed in Table I.

Regarding complications, moderate facial hypoesthesia occurred in $7.1-100 \%$ of patients who underwent RFT (Table II) $(17,19-23,26-31,34,35,40,41,45,46,52,58,60,61$, 63-66,69), whereas bothersome dysesthesia occurred in $0-36 \%$ of patients $(12,18,22,26,28,29,31,33,36,37,40-42,45,47$, $48,50,51,53-56,59,62,65,68,69)$ and anesthesia dolorosa was present in $0-9.6 \%$ of patients $(31,36,37,47-51,53,55-57,68,69)$. The percentage ranges of patients identified for the other complications examined were as follows: Masticatory weakness in $0-77.5 \%(12,17,18,20,21,26-29,31,33,34,36,40,42,43,45$, $47-55,59,60,62-64,66,68)$, facial swelling in $0-37.5 \%(17,18,21$, $31,33,35,43,59-61,64,68)$, corneal involvement in $0-72.2 \%$ (17, $18,21,23,26-29,31,34,36,40-43,45,47-57,60-66,68)$, sixth nerve palsy in $0-1.7 \%(26,28,35,47,49,52,68)$, otalgia or hypoacousia in $0.21-8.66 \%(26,36,43,52,62)$, meningitis in $0.06-3.6 \%(27,29$, $36,53,55,56,68)$, nausea or vomiting in $0-12.2 \%(20,59,61-63)$, cerebrospinal fluid leakage in $0-32.1 \%(36,52,61,12,69)$ and carotid artery puncture in $0.79 \%$ of patients (43).

\section{Discussion}

The mean initial pain relief provided by RFT was $95.31 \%$, whereas the range was 77.8-100\%. Although the lowest reported initial pain relief rate was $77.8 \%, 92.4 \%$ of the studies had an initial pain relief rate of $>90 \%$. A longer follow-up period was associated with a higher number of relapses. Recurrence following RFT was found in $69.57 \%$ of the reported studies and the peak range was 1-2 years $(17,18,20-22,24-32,34-37,39$, $41,46,50,51,59-65,12,67)$. The median value of the mean time to pain recurrence was $26.1 \pm 11.5$ months (28).

Among the studies assessed, moderate facial hypoesthesia was the most common complication of RFT, although sensory impairment may be necessary for optimal clinical results (70). Bothersome dysesthesia is also common with RFT but it has rarely been mentioned in the past decade $(17,19-21,23,27,52$, 59-61,63,64). Anesthesia dolorosa is common following RFT $(31,36,53,56,12)$, although this complication has rarely been mentioned in the past decade. Complications of corneal involvement are common in RFT and their incidence was particularly high when RFT was used to treat the ophthalmic division (V1) of TN $(23,61)$. During RFT treatment, precise location of the needle tip selectively damages the unmyelinated fine fibers in the lesion area, thereby reducing the occurrence of complications and relapses (7-12). This result is consistent with those of a previous study by our group (19). The only complication of the treatment, which combines the stereotactic approach with 3D CT reconstruction and RFT of the Gasserian ganglion (19), was moderate facial hypoesthesia. Facial swelling occurs mostly due to soft-tissue damage caused by repeated punctures or damage to blood vessels during puncture. Its risk is reduced by accurate puncture. Although masticatory weakness was mentioned as a complication of $\mathrm{RFT}$, it is more frequent and severe following percutaneous balloon compression (PBC) (71-76).

Several factors exist that influence ablative interventions. Koning et al (27) investigated sensory stimulation and the side effects of RFT for TN. They concluded that low sensory stimulation increased hypesthesia and that high stimulation may be less effective. However, this study did not determine the optimal sensory stimulation level.

Continuous radiofrequency (CRF), pulsed radiofrequency (PRF) and combined CRF with PRF (CCPRF) are three radiofrequency treatments used for TN. Although CRF has more complications than PRF, the majority of them are minor and transient. Compared with PRF, CRF exhibits a higher satisfaction rate and lower recurrence rate (64). Therefore, PRF is not considered an effective method for TN (69). CCPRF aided the elimination of postoperative complications (77) and achieved a level of pain relief comparable to that afforded by CRF (78). Yao et al (61) recommended the clinical use of CCPRF for treating V1 TN.

The radiofrequency temperature is another factor that affects the outcomes of RFT, although no current standard exists for the selection of the CRF temperature required for TN treatment. Yao et al $(60,62)$ reported that $68^{\circ} \mathrm{C}$ was the optimal radiofrequency temperature for treating the maxillary (V2) and mandibular (V3) division of idiopathic TN (62) and bilateral idiopathic TN (60). Zhao et al (77) suggested that $70^{\circ} \mathrm{C}$ was the optimal temperature for RFT. Tang et al (52) recommended a temperature of $75^{\circ} \mathrm{C}$ for idiopathic TN. Wu et al (79) reported that patient satisfaction was improved when the temperature range was $68-70^{\circ} \mathrm{C}$, whereas the efficiency was improved at a temperature range of $66-80^{\circ} \mathrm{C}$. In other studies, the temperature range of $60-65^{\circ} \mathrm{C}$ for $\mathrm{V} 1$ and the temperatures of $72^{\circ} \mathrm{C}$ and $75^{\circ} \mathrm{C}$ for $\mathrm{V} 2$ and $\mathrm{V} 2 / \mathrm{V} 3 \mathrm{TN}$, respectively, were used and the results indicated excellent patient satisfaction $(19,80)$. For $\mathrm{PRF}$, a temperature range of $45-50^{\circ} \mathrm{C}$ has been recommended, particularly for elderly patients $(77,79)$.

In a non-RCT by Huang et al (18) V3 TN was treated under CT guidance with both bipolar and monopolar techniques. This study indicated that bipolar RFT exhibited a more favorable efficacy and recurrence rate than monopolar RFT, which was 
likely due to larger lesion sizes in the bipolar RFT group (18). However, due to the small sample size, higher-quality evidence from larger-scale, well-designed, RCTs is required.

Huang et al (31) compared the efficacy of classic and mixed TN. It was indicated that $48.1 \%$ of patients with mixed TN reported improvements following RFT compared with $86.7 \%$ of patients with classic TN. Similarly, Kosugi et al (24) compared the long-term efficacy of isolated $\mathrm{V} 2 \mathrm{TN}$, isolated V3 TN and mixed TN. The data demonstrated that the pain relief time of isolated V3 TN was longer than that of V2 and mixed TN. RFT was effective for classic TN and was relatively reliable for mixed TN. RFT had a positive outcome when used to manage provoked paroxysmal pain $\mathrm{TN}$ or mixed pain (provoked and constant pain) TN compared with constant, dull, aching pain TN (25). Degn and Brennum (30) reported that RFT was an effective intervention for type 1 TN (brief lancinating pain) but not for type $2 \mathrm{TN}$ (continuous pain).

Liu et al (20) compared the efficacy and complications between RFT treatment of initial TN and recurrent TN. They indicated that the efficacy and the complication rate of repeated TN treated by RFT was similar to that of the initial TN.

Filippiadis et al (58) described an alternative approach for RFT, which included the entry point from the lateral side near the zygomatic bone. This approach used to be performed under local anesthesia (81-85) and this was the first time that it was applied to RFT. Furthermore, Ding et al (86) described a submandibular approach through a mandibular angle to reach the foramen ovale. These studies suggested the use of an alternative approach instead of the Härtel anterior approach that may reduce the complication rate, obtain long-term pain control of TN and achieve higher target selectivity for RFT.

In conclusion, in the present systematic review, the role of RFT in pain management provided to patients with TN was analyzed. RFT offered a high initial pain relief rate and a long pain-free interval after treatment. The recurrence rate was acceptable and the recurrence peak was 1-2 years. RFT may be repeated easily if pain recurs and has a longer learning curve for junior surgeons compared with that of PBC.

There are no sham-controlled or comparative trials on any neurosurgical intervention, which is a limitation of the present study. However, the incidence of complications was low and the majority of the complications were able to be recovered. Owing to the considerable heterogeneity and risk of bias in the included studies, strong conclusions could not be drawn. Additional high-quality RCTs assessing the role of RFT in TN management are required to strengthen the current evidence. The reduction of the difficulty of RFT puncture and of the recurrence and complication rates following RFT treatment are the main issues that need to be addressed in future studies.

\section{Acknowledgements}

Not applicable.

\section{Funding}

This work was supported by grants from the Science and Technology Department of Jilin Province, China (grant nos. 20110472 and 20150204072 SF).

\section{Availability of data and materials}

All data generated or analyzed during this study are included in this published article and its supplementary files.

\section{Authors' contributions}

ZMW, ZJW, KL and XS acquired, analyzed and interpreted the data. ZJW and KL confirm the authenticity of all the raw data. ZMW drafted the manuscript. CD and YT conceived and designed the current study, and revised the manuscript for important intellectual content. Each author participated sufficiently in the work to take public responsibility for appropriate portions of the content and agreed to be accountable for all aspects of the work in ensuring that questions related to the accuracy or integrity of any part of the work are appropriately investigated and resolved. All authors read and approved the final manuscript.

\section{Ethics approval and consent to participate}

Not applicable.

\section{Patient consent for publication}

Not applicable.

\section{Competing interests}

The authors declare that they have no competing interests.

\section{References}

1. International Association for the Study of Pain (IASP): Classification of chronic pain. Descriptors of chronic pain syndromes and definitions of pain terms. 2nd edition. IASP Press, Washington, DC, 1994.

2. Zakrzewska JM and McMillan R: Trigeminal neuralgia: The diagnosis and management of this excruciating and poorly understood facial pain. Postgrad Med J 87: 410-416, 2011.

3. Zakrzewska JM, Lopez BC, Kim SE and Coakham HB: Patient reports of satisfaction after microvascular decompression and partial sensory rhizotomy for trigeminal neuralgia. Neurosurgery 56: 1304-1311, 2005.

4. Réthi A: The Electrolytic Treatment of Trigeminal Neuralgia. Munch Med Wochenschr 60: 295-296, 1913 (In German).

5. Sweet WG: Proceedings: Analgesia dolorosa after differential retrogasserian thermal or mechanical rhizotomy: Tactics employed to decrease its influence. J Neurol Neurosurg Psychiatry 38: 407, 1975.

6. Bendtsen L, Zakrzewska JM, Heinskou TB, Hodaie M, Leal PR, Nurmikko T, Obermann M, Cruccu G and Maarbjerg S: Advances in diagnosis, classification, pathophysiology, and management of trigeminal neuralgia. Lancet Neurol 19: 784-796, 2020.

7. Zhang WC, Zhong WX, Li ST, Zheng XS, Yang M and Shi J: Neuronavigator-guided percutaneous radiofrequency thermocoagulation in the treatment of trigeminal neuralgia. Ir J Med Sci 181: 7-13, 2012.

8. Zhao S, Deng M, Cai H, Meng Q, Fang W, Ke J and Long X: Clinical efficacy evaluation for treating trigeminal neuralgia using a personalized digital guide plate-assisted temperature-controlled radiofrequency. J Craniofac Surg 29: 1322-1326, 2018.

9. Zhang LG, Deng MH, Long X and Wang ZZ: 3D printing navigation template-guided percutaneous radiofrequency thermocoagulation for V2 trigeminal neuralgia treatment. Hua Xi Kou Qiang Yi Xue Za Zhi 36: 662-666, 2018 (In Chinese).

10. Lu LJ, Han Y, Huai HB and Xie H: 3D printing puncture navigation module-guided percutaneous radiofrequency thermocoagulation for treatment of trigeminal neuralgia. Chin J Pain Med 12: 914-918, 2015 (In Chinese). 
11. Hinteregger M, Zschiegner F, Lirk P, Ladner E, Goeschl A, Gaber O, Moser P, Lorenz I and Kolbitsch C: A new guidance device facilitates percutaneous puncture of the foramen ovale in human cadavers. Can J Anaesth 51: 990-992, 2004.

12. Xu SJ, Zhang WH, Chen T, Wu CY and Zhou MD: Neuronavigator-guided percutaneous radiofrequency thermocoagulation in the treatment of intractable trigeminal neuralgia. Chin Med J (Engl)S 119: 1528-1535, 2006.

13. Mandat T, Brozyna B, Krzymanski G and Podgorski JK: An image-guided, noninvasive method of cannulation of the foramen ovale for awake, percutaneous radiof requency rhizotomy. J Neurosurg 111: 1223-1225, 2009.

14. Liberati A, Altman DG, Tetzlaff J, Mulrow C, Gøtzsche PC, Ioannidis JP, Clarke M, Devereaux PJ, Kleijnen J and Moher D: The PRISMA statement for reporting systematic reviews and meta-analyses of studies that evaluate healthcare interventions: Explanation and elaboration. BMJ 339: b2700, 2009

15. Higgins JPT, Altman DG, Gøtzsche PC, Jüni P, Moher D, Oxman AD, Savovic J, Schulz KF, Weeks L, Sterne JA, et al: The cochrane collaboration's tool for assessing risk of bias in randomised trials. BMJ 343: d5928, 2011.

16. Sterne JA, Hernán MA, Reeves BC, Savović J, Berkman ND, Viswanathan M, Henry D, Altman DG, Ansari MT, Boutron I, et al: ROBINS-I: A tool for assessing risk of bias in non-randomised studies of interventions. BMJ 355: i4919, 2016.

17. Xue TQ, Zhang QX, Bian H, Zhou PC, Liu C, Niu SF, Wang ZB, Shi WJ and Yan CY: Radiofrequency thermocoagulation through foramen rotundum versus foramen ovale for the treatment of V2 trigeminal neuralgia. Pain Physician 22: E609-E614, 2019.

18. Huang B, Xie K, Chen Y, Wu J and Yao M: Bipolar radiofrequency ablation of mandibular branch for refractory V3 trigeminal neuralgia. J Pain Res 12: 1465-1474, 2019.

19. Guo Z, Wang Z, Li K, Du C, Zhao X, Cheng M and Tian Y Unconventional facial entry points confirmed using a 3D CT reconstruction-guided stereotactic approach to radiofrequency thermocoagulation for the treatment of trigeminal neuralgia: A series of case reports. Pain Med 20: 1551-1558, 2019.

20. Liu G, Du Y, Wang X and Ren Y: Efficacy and safety of repeated percutaneous radiofrequency thermocoagulation for recurrent trigeminal neuralgia. Front Neurol 9: 1189, 2018

21. Telischak NA, Heit JJ, Campos LW, Choudhri OA, Do HM and Qian X: Fluoroscopic C-Arm and CT-guided selective radiofrequency ablation for trigeminal and glossopharyngeal Facial pain syndromes. Pain Med 19: 130-141, 2018.

22. Noorani I, Lodge A, Vajramani G and Sparrow O: Comparing percutaneous treatments of trigeminal neuralgia: 19 years of experience in a single centre. Stereotact Funct Neurosurg 94: $75-85,2016$.

23. Huang Q, Liu X, Chen J, Bao C, Liu D, Fang Z, Liang X, Lu Z and Wan L: The effectiveness and safety of thermocoagulation radiofrequency treatment of the ophthalmic division (V1) and/or maxillary (V2) and mandibular (V3) division in idiopathic trigeminal neuralgia: An observational study. Pain Physician 19: E1041-E1047, 2016.

24. Kosugi S, Shiotani M, Otsuka Y, Suzuki T, Katori N, Hashiguchi S and Morisaki H: Long-term outcomes of percutaneous radiofrequency thermocoagulation of gasserian ganglion for $2 \mathrm{nd}-$ and multiple-division trigeminal neuralgia. Pain Pract 15: 223-228, 2015.

25. Jin HS, Shin JY, Kim YC, Lee SC, Choi EJ, Lee PB and Moon JY: Predictive factors associated with success and failure for radiofrequency thermocoagulation in patients with trigeminal neuralgia. Pain Physician 18: 537-545, 2015.

26. Tang YZ, Jin D, Bian JJ, Li XY, Lai GH and Ni JX: Long-term outcome of computed tomography-guided percutaneous radiofrequency thermocoagulation for classic trigeminal neuralgia patients older than 70 years. J Craniofac Surg 25: 1292-1295, 2014.

27. Koning MV, Koning NJ, Koning HM and van Kleef $M$ : Relationship between sensory stimulation and side effects in percutaneous radiofrequency treatment of the trigeminal ganglion. Pain Pract 14: 581-587, 2014.

28. Son BC, Kim HS, Kim IS, Yang SH and Lee SW: Percutaneous radiofrequency thermocoagulation under fluoroscopic image-guidance for idiopathic trigeminal neuralgia. J Korean Neurosurg Soc 50: 446-452, 2011.

29. Fouad W: Management of trigeminal neuralgia by radiofrequency thermocoagulation. Alexandria J Med 47: 79-86, 2011.
30. Degn J and Brennum J: Surgical treatment of trigeminal neuralgia. Results from the use of glycerol injection, microvascular decompression, and rhizotomia. Acta Neurochir (Wien) 152: 2125-2132, 2010

31. Huang Y, Ni J, Wu B, He M, Yang L and Wang Q: Percutaneous radiofrequency thermocoagulation for the treatment of different types of trigeminal neuralgia: Evaluation of quality of life and outcomes. J Huazhong Univ Sci Technolog Med Sci 30: 403-407, 2010.

32. Haridas A, Mathewson C and Eljamel S: Long-term results of 405 refractory trigeminal neuralgia surgeries in 256 patients. Zentralbl Neurochir 69: 170-174, 2008.

33. Fraioli MF, Cristino B, Moschettoni L, Cacciotti G and Fraioli C: Validity of percutaneous controlled radiofrequency thermocoagulation in the treatment of isolated third division trigeminal neuralgia. Surg Neurol 71: 180-183, 2009.

34. Liu M, Wu CY, Liu YG, Wang HW and Meng FG: Three-dimensional computed tomography-guided radiofrequency trigeminal rhizotomy for treatment of idiopathic trigeminal neuralgia. Chin Med Sci J 20: 206-209, 2005.

35. Teixeira MJ, Siqueira SRDT and Almeida GM: Percutaneous radiofrequency rhizotomy and neurovascular decompression of the trigeminal nerve for the treatment of facial pain. Arq Neuropsiquiatr 64: 983-989, 2006.

36. Kanpolat Y, Savas A, Bekar A and Berk C: Percutaneous controlled radiofrequency trigeminal rhizotomy for the treatment of idiopathic trigeminal neuralgia: 25 -year experience with 1,600 patients. Neurosurgery 48: 524-532, 2001.

37. Tronnier VM, Rasche D, Hamer J, Kienle AL and Kunze S: Treatment of idiopathic trigeminal neuralgia: Comparison of long-term outcome after radiofrequency rhizotomy and microvascular decompression. Neurosurgery 48: 1261-1267, 2001.

38. Lee KH, Chang JW, Park YG and Chung SS: Microvascular decompression and percutaneous rhizotomy in trigeminal neuralgia. Stereotact Funct Neurosurg 68: 196-199, 1997.

39. Oturai AB, Jensen K, Eriksen J and Madsen F: Neurosurgery for trigeminal neuralgia: Comparison of alcohol block, neurectomy, and radiofrequency coagulation. Clin J Pain 12: 311-315, 1996.

40. Taha JM, Tew JM and Buncher CR: A prospective 15-year follow up of 154 consecutive patients with trigeminal neuralgia treated by percutaneous stereotactic radiofrequency thermal rhizotomy. J Neurosurg 83: 989-993, 1995.

41. Tan LK, Robinson SN and Chatterjee S: Glycerol versus radiofrequency rhizotomy-a comparison of their efficacy in the treatment of trigeminal neuralgia. Br J Neurosurg 9: 165-169, 1995.

42. Broggi G, Franzini A, Giorgi C, Servello D and Brock S: Trigeminal neuralgia: New surgical strategies. Acta Neurochir Suppl (Wien) 58: 171-173, 1993.

43. Hamid AI, Qureshi AA and Bhatti IH: Percutaneous radiofrequency retrogasserian rhizotomy for trigeminal neuralgia. J Pak Med Assoc 43: 132-133, 1993.

44. Zakrzewska JM and Thomas DG: Patient's assessment of outcome after three surgical procedures for the management of trigeminal neuralgia. Acta Neurochir (Wien) 122: 225-230, 1993.

45. Moraci A, Buonaiuto C, Punzo A, Parlato C and Amalfi R: Trigeminal neuralgia treated by percutaneous thermocoagulation. Comparative analysis of percutaneous thermocoagulation and other surgical procedures. Neurochirurgia (Stuttg) 35: 48-53, 1992.

46. Meglio M, Cioni B, Moles A and Visocchi M: Microvascular decompression versus percutaneous procedures for typical trigeminal neuralgia: Personal experience. Stereotact Funct Neurosurg 54-55: 76-79, 1990.

47. Broggi G, Franzini A, Lasio G, Giorgi C and Servello D: Long-term results of percutaneous retrogasserian thermorhizotomy for 'essential' trigeminal neuralgia: Considerations in 1000 consecutive patients. Neurosurgery 26: 783-786, 1990.

48. Fraioli B, Esposito V, Guidetti B, Cruccu G and Manfredi M Treatment of trigeminal neuralgia by thermocoagulation, glycerolization, and percutaneous compression of the gasserian ganglion and/or retrogasserian rootlets: Long-term results and therapeutic protocol. Neurosurgery 24: 239-245, 1989.

49. Frank F and Fabrizi AP: Percutaneous surgical treatment of trigeminal neuralgia. Acta Neurochir (Wien) 97: 128-130, 1989.

50. Mittal B and Thomas D: Controlled thermocoagulation in trigeminal neuralgia. J Neurol Neurosurg Psychiatry 49: 932-936, 1986.

51. Latchaw JP, Hardy RW, Forsythe SB and Cook AF: Trigeminal neuralgia treated by radiofrequency coagulation. J Neurosurg 59: $479-484,1983$. 
52. Tang YZ, Yang LQ, Yue JN, Wang XP, He LL and Ni JX: The optimal radiofrequency temperature in radiofrequency thermocoagulation for idiopathic trigeminal neuralgia: A cohort study. Medicine (Baltimore) 95: e4103, 2016.

53. Mathews ES and Scrivani SJ: Percutaneous stereotactic radiofrequency thermal rhizotomy for the treatment of trigeminal neuralgia. Mt Sinai J Med 67: 288-299, 2000.

54. Yoon KB, Wiles JR, Miles JB and Nurmikko TJ: Long-term outcome of percutaneous thermocoagulation for trigeminal neuralgia. Anaesthesia 54: 803-808, 1999.

55. Tew Jr J and Taha J: Percutaneous rhizotomy in the treatment of intractable facial pain (trigeminal, glossopharyngeal, and vagal nerves). In: Operative Neurosurgical Techniques: Indications, Methods, and Results. WB Saunders Co., Philadelphia, PA, pp1469-1484, 1995.

56. Ischia S, Luzzani A, Polati E and Ischia A: Percutaneous controlled thermocoagulation in the treatment of trigeminal neuralgia. Clin J Pain 6: 96-104, 1990.

57. Burchiel KJ, Steege TD, Howe JF and Loeser JD: Comparison of percutaneous radiofrequency gangliolysis and microvascula decompression for the surgical management of tic douloureux. Neurosurgery 9: 111-119, 1981.

58. Filippiadis DK, Markoutsas D, Mazioti A, Tsoukalos G, Papakonstantinou O, Stamatis P, Kelekis A and Tzavoulis D: Computed tomography-guided radiofrequency thermocoagulation of the gasserian ganglion using an alternative to hartel anterior approach: A bicentral study. Pain Physician 23: 293-298, 2020.

59. Elawamy A, Abdalla EEM and Shehata GA: Effects of pulsed versus conventional versus combined radiofrequency for the treatment of trigeminal neuralgia: A prospective study. Pain physician 20: E873-E881, 2017.

60. Yao P, Hong T, Wang ZB, Ma JM, Zhu YQ, Li HX, Ding YY, Jiang CL and Pan SN: Treatment of bilateral idiopathic trigeminal neuralgia by radiofrequency thermocoagulation at different temperatures. Medicine (Baltimore) 95: e4274, 2016.

61. Yao P, Hong T, Zhu YQ, Li HX, Wang ZB, Ding YY, Ma JM and Pan SN: Efficacy and safety of continuous radiofrequency thermocoagulation plus pulsed radiofrequency for treatment of V1 trigeminal neuralgia: A prospective cohort study. Medicine (Baltimore) 95: e5247, 2016.

62. Yao P, Deng YY, Hong T, Wang ZB, Ma JM, Zhu YQ, Li HX, Ding YY and Pan SN: Radiofrequency thermocoagulation for V2/V3 idiopathic trigeminal neuralgia: Effect of treatment temperatures on long-term clinical outcomes: A cohort study. Medicine (Baltimore) 95: e4019, 2016.

63. Singh S, Verma R, Kumar M, Rastogi V and Bogra J: Experience with conventional radiofrequency thermorhizotomy in patients with failed medical management for trigeminal neuralgia. Korean J Pain 27: 260-265, 2014.

64. Huang B, Yao M, Feng Z, Guo J, Zereshki A, Leong M and Qian X: CT-guided percutaneous infrazygomatic radiofrequency neurolysis through foramen rotundum to treat V2 trigeminal neuralgia. Pain Med 15: 1418-1428, 2014.

65. Udupi BP, Chouhan RS, Dash HH, Bithal PK and Prabhakar H: Comparative evaluation of percutaneous retrogasserian glycero rhizolysis and radiofrequency thermocoagulation techniques in the management of trigeminal neuralgia. Neurosurgery 70 : 407-412, 2012.

66. Huibin Q, Jianxing L, Guangyu $\mathrm{H}$ and Dianen F: The treatment of first division idiopathic trigeminal neuralgia with radiofrequency thermocoagulation of the peripheral branches compared to conventional radiofrequency. J Clin Neurosci 16: 1425-1429, 2009.

67. Zakrzewska JM, Jassim S and Bulman SJ: A prospective, longitudinal study on patients with trigeminal neuralgia who underwent radiofrequency thermocoagulation of the Gasserian ganglion. Pain 79: 51-58, 1999.

68. Scrivani SJ, Keith DA, Mathews ES and Kaban LB: Percutaneous stereotactic differential radiofrequency thermal rhizotomy for the treatment of trigeminal neuralgia. J Oral Maxillofac Surg 57: 104-111, 1999.

69. Erdine S, Ozyalcin NS, Cimen A, Celik M, Talu GK and Disci R: Comparison of pulsed radiofrequency with conventional radiofrequency in the treatment of idiopathic trigeminal neuralgia. Eur J Pain 11: 309-313, 2007.
70. Laitinen LV, Brophy BP and Bergenheim AT: Sensory disturbance following percutaneous retrogasserian glycerol rhizotomy. Br J Neurosurg 3: 471-477, 1989.

71. de Siqueira SRDT, da Nóbrega JCM, de Siqueira JTT and Teixeira MJ: Frequency of postoperative complications after balloon compression for idiopathic trigeminal neuralgia: Prospective study. Oral Surg Oral Med Oral Pathol Oral Radiol Endod 102: e39-e45, 2006.

72. Du Y, Yang D, Dong X, Du Q, Wang H and Yu W: Percutaneous balloon compression (PBC) of trigeminal ganglion for recurrent trigeminal neuralgia after microvascular decompression (MVD). Ir J Med Sci 184: 745-751, 2015.

73. Brown JA and Gouda JJ: Percutaneous balloon compression of the trigeminal nerve. Neurosurg Clin N Am 8: 53-62, 1997.

74. Teo MK and Suttner NJ: Effective management of lower divisional pain in trigeminal neuralgia using balloon traction. $\mathrm{Br}$ J Neurosurg 29: 343-346, 2015.

75. Abdennebi B and Guenane L: Technical considerations and outcome assessment in retrogasserian balloon compression for treatment of trigeminal neuralgia. Series of 901 patients. Surg Neurol Int 5: 118, 2014

76. Chen JF, Tu PH and Lee ST: Repeated percutaneous balloon compression for recurrent trigeminal neuralgia: A long-term study. World Neurosurgery 77: 352-356, 2012

77. Zhao WX, Wang Q, He MW, Yang LQ, Wu BS and Ni JX: Radiofrequency thermocoagulation combined with pulsed radiofrequency helps relieve postoperative complications of trigeminal neuralgia. Genet Mol Res 14: 7616-7623, 2015.

78. Li X, Ni J, Yang L, Wu B, He M, Zhang X, Ma L and Sun H: A prospective study of Gasserian ganglion pulsed radiofrequency combined with continuous radiofrequency for the treatment of trigeminal neuralgia. J Clin Neurosci 19: 824-828, 2012.

79. Wu H, Zhou J, Chen J, Gu Y, Shi L and Ni H: Therapeutic efficacy and safety of radiofrequency ablation for the treatment of trigeminal neuralgia: A systematic review and meta-analysis. J Pain Res 12: 423-441, 2019.

80. Guo Z, Wu B, Du C, Cheng M and Tian Y: Stereotactic approach combined with 3D CT reconstruction for difficult-to-access foramen ovale on radiofrequency thermocoagulation of the gasserian ganglion for trigeminal neuralgia. Pain Med 17: 1704-1716, 2016.

81. Kara A, Kurtoglu Z, Tekdemir I, Elhan A, Uzmansel D and Yapici D: Measurements for the direct approach to the oval foramen to apply mandibular nerve blockade. J Craniofac Surg 23: 938-942, 2012.

82. Kodama Y, Seo K, Tanaka R, Arashiyama T, Ajima H and Takagi R: Placement of mandibular nerve block using computed tomography to locate the foramen ovale in a patient with severe dislocation after segmental mandiblectomy. Br J Oral Maxillofac Surg 47: 407-408, 2009.

83. Plantevin F, Pascal J, Morel J, Roussier M, Charier D, Prades JM, Auboyer C and Molliex S: Effect of mandibular nerve block on postoperative analgesia in patients undergoing oropharyngeal carcinoma surgery under general anaesthesia. Br J Anaesth 99: 708-712, 2007.

84. Stajcic Z and Todorovic L: Blocks of the foramen rotundum and the oval foramen: A reappraisal of extraoral maxillary and mandibular nerve injections. Br J Oral Maxillofac Surg 35: 328-333, 1997.

85. Umino M, Kohase H, Ideguchi S and Sakurai N: Long-term pain control in trigeminal neuralgia with local anesthetics using an indwelling catheter in the mandibular nerve. Clin J Pain 18: 196-199, 2002

86. Ding W, Chen S, Wang R, Cai J, Cheng Y, Yu L, Li Q, Deng F, Zhu $\mathrm{S}$ and $\mathrm{Yu} \mathrm{W}$ : Percutaneous radiofrequency thermocoagulation for trigeminal neuralgia using neuronavigation-guided puncture from a mandibular angle. Medicine (Baltimore) 95: e4940, 2016.

This work is licensed under a Creative Commons Attribution-NonCommercial-NoDerivatives 4.0 International (CC BY-NC-ND 4.0) License. 